\title{
Ritus Ruwatan Murwakala di Surakarta
}

\author{
Lies Mariani \\ Departemen Antropologi, Universitas Padjadjaran \\ liesmar895@gmail.com
}

\begin{abstract}
This article discusses Ruwatan Murwakala as one part of rites of passage in Java. This sacred ritual associated with life cycle has been practiced and has been considered relevant among Javanese. This ritual has become part of tangible and intangible oral tradition in Indonesia. Drawing from Van Gennep theory on rites of passage, this ritual consists of stages which represent life cycles such as separation in the first stage, marge or liminal (transition) in the second stage, and aggregation or rites of incorporation (recovery) in the third stage. This article also discusses the importance role of dalang or the ritual leader. Dalang is not merely play his role in the ritual but has become a mediator in the creation of a balance and harmonious relationship among beings in the cosmos; which has been characterized by a harmonious relationship between human beings and supernatural powers and the natural power.
\end{abstract}

Keywords: Ruwatan, Murwakala, Rites, Life cycle, Folklore

\begin{abstract}
Abstrak
Artikel ini membahas Ruwatan Murwakala sebagai salah satu bentuk ritus peralihan di Jawa. Ritual sakral terkait daur hidup ini masih dilaksanakan oleh masyarakat Jawa dan masih dianggap relevan. Ritus ini juga menjadi bagian dari tradisi lisan dan tulisan yang bersifat tangible dan intangible. Merujuk pada konsep Van Gennep mengenai ritus peralihan, ritual ini memiliki tahapan sesuai tahapan dalam ritus peralihan manusia yaitu separations atau rites of separation (perpisahan) pada tahap pertama, marge atau rites of liminal (peralihan) pada tahap kedua, dan aggregation atau rites of incorporation (pemulihan) pada tahap ketiga. Artikel ini juga mendiskusikan peran penting dalang dalam prosesi ritual. Ia tidak hanya berperan memimpin ritual tetapi juga berperan sebagai mediator bagi terwujudnya keseimbangan tertib kosmos dalam masyarakat; yang ditandai adanya hubungan harmonis antara sesama manusia dengan kekuatan gaib dan alam semesta.
\end{abstract}

Kata kunci: Ritus, Ruwatan, Murwakala, Daur hidup, Tradisi lisan

\section{Pendahuluan}

Upacara Ruwatan Murwakala adalah salah satu ritual yang masih dilakukan oleh masyarakat Jawa hingga saat ini. Upacara ini dicirikan oleh pagelaran wayang yang memiliki tujuan khusus yaitu "wayangan dianggo srana nulak kacilakan kang bakal tumiba marang bocah mecahake pipisan" yang artinya pagelaran wayang sebagai sarana menolak sial dan celaka yang akan terjadi pada anak-anak yang memecahkan pipisan atau alat penggiling jejamuan yang terbuat dari batu (Poerwadarminta 1937: 328). Secara etimologis, ruwatan berasal dari kata ruwat: dibuat tidak berdaya, hancur, binasa, kejahatan, kutukan, dan pengaruh jahat. Kata turunannya adalah ayruwa, rumuwa, rinuwat artinya, menghancurkan, membebaskan dari roh jahat, dan menyebabkan tidak berdaya (Zoetmulder, 1995: 967). Sedangkan kata 
Murwakala berakar dari kata murwa ${ }^{1}$ atau pūrwa $a^{2}$ yang berarti awal mula; dan $k a l a^{3}$ yang berarti waktu. Murwakala berarti awal mula sang waktu atau sangat ${ }^{4}$. Pūrwakala dalam bahasa Sansekerta bermakna pada waktu dahulu ${ }^{5}$. Pengertian lain dari Murwakala atau Pūrwakala adalah awal mula sang waktu atau

\footnotetext{
${ }^{1}$ Dalam Javaans-Nederlands Handwoordenboek, moerwa (ni) artinya mulai pembuatan pertama kali, atau sebagai purwa (Pigeaud, 1937: 295).

${ }^{2}$ Pūrwa dari bahasa Sanssekrta artinya permulaan, pertama-tama, pada masa yang lalu, pada zaman dahulu. Pūrwakala juga berarti waktu dahulu (Zoetmulder 1995: 887-888). Dalam Baoesastra Djawa berarti: (s) kw: 1. wiwitan, kang disik; 2 mula; 3 wetan. wayang poerwa, moerwa
} (1939:504). Dalam Javaans-Nederlands Handwoordenboek, poerwa artinya awal, pertama, dan kala artinya waktu (1937: 475).

${ }^{3}$ Dalam buku Bausastra Djawa, kala mempunyai beberapa arti: 1. jiret, pasangan untuk menjirat burung, 2. piala, ala, kejahatan, Jahat, buta, raksasa, setan/jin, 3 bangsa hewan yang menyengat, kalajengking, kalamenthel, 4. waktu, mangsa- musim itu, ketika(dek nalika), kala-kala, tidak ajeg, tidak pasti (Poerwadarminta, 1939: 181 dan Pigeaud, 1937: 161).

${ }^{4}$ Dalam Javaans-Nederlands Handwoordenboek, Sangat memiliki arti: 1. bagian dari hari; 2 . saat hari bahagia, hari untuk menikah, dihitung dengan ramalan (Pigeaud, 1937:509). Dalam Baoesastra Djawa: 1. golongan peprincéning waktu ing sadina-dinané (sadina dipérang dadi 2), sagolongane nganggo dijenengi asmane Nabi oet. Malaekat); 2. waktu sing betjik déwé ing sadjroning dina (kanggo ngijabaké pangantén) (Poerwadarminta, 1939: 544). Dalam pengucapan Bahasa Jawa, kata ini mempunyai pengertian perhitungan 'tepat ketika itu' yang didasarkan pada peredaran matahari (peredaran kalacakra) dipercaya memiliki saat gangguan atau kala-bendu (benah, tulah, atau sebab-akibat), serta adanya pembagian empat saat: 1. pada saat terbit fajar atau sa'at gagat esuk, gagating raina; 2 tengah hari saat matahari tepat di atas kepala atau sa'atsurya tumumpang aksa; 3. saat matahari terbenam senjakala atau sa'atsandyakala; 4 . tengah malam saat bulan purnama tepat di atas kepala atau sa'atcandra tumumpang aksa (Herusatoto 2012: 39). Sangat dalam padanan pengucapan bahasa Indonesia mempunyai pengertian waktu (yang pendek sekali) atau waktu yang bertalian dengan baik-buruk (untung-malang), saat yang naas atau saat yang sempurna (KBBI, 1995: 857).

${ }^{5}$ Dalam naskah Ramayana: 8.148: kathācarita pūrwakāla (Zoetmulder, 1995: 888). purwaning dumadi (awal mula ada atau awal eksistensi sesuatu hal ${ }^{6}$.

Upacara Ruwatan Murwakala bertujuan meruwat golongan sukěrta ${ }^{7}$ Sukérta berakar dari kata sukěr , ěwuh, rěkasa angěl, reged-diregeti, jenes, sedih, susahdisusahake yang memiki arti 'terhalang', 'terhambat', 'sedang susah', 'dalam kesulitan', dan 'merasa gelisah' (Poerwadarminta, 1937: 570, Zoetmulder, 1995: 1137). Golongan sukěrta adalah golongan manusia yang sepanjang perjalanan waktu (kala) hidupnya ditengarai akan mengalami gangguan atau bencana atau kesengsaraan. Golongan ini memiliki kriteria tertentu yang mereka dikategorikan sebagai golongan orang dengan kondisi atau situasi yang dianggap berdosa atau kotor sehingga perlu diruwat atau dibebaskan melalui sebuah ritual (Herusatoto, 2012:46-47).

Keluarga yang memiliki anak yang termasuk golongan sukěrta biasanya selalu merasa khawatir dengan status anaknya. Mereka percaya bahwa dengan kondisi tersebut, anak mereka terancam dimangsa Batara Kala, raksasa yang menyimbolkan marabahaya dalam kepercayaan Jawa. Oleh karena itu setiap orang tua dari anak sukerta berkeinginan membebaskan anak mereka dari bahaya itu dengan melalui upacara ruwatan. Upacara Ruwatan Murwakala adalah ritual yang berfungsi sebagai sarana pengentasan, pembebasan, dan penyucian bagi golongan sukěrta yang dianggap mempunyai keadaan tidak ideal.

\footnotetext{
${ }^{6}$ Mengutip Budiono Herusatoto dalam bukunya Mitologi Jawa, awal dimulainya kehidupan manusia atau saat kelahiran awal mula keberadaan manusia ke dunia” (2012:46)

${ }^{7}$ Dalam beberapa kitab cerita dan pedoman, jumlah ruwatan tidak sama jumlahnya. Ini terdapat antara lain dalam: kitab Centhini jumlah sukérta ada 60 orang, Serat Murwakala, karangan Citrakusuma, jumlah sukérta ada 147 orang, dalam Serat Sarasilah Wayang Purwa, karangan S. Padmosoekotjo jumlah sukérta ada 22 orang (Subalidinata, 1985: 105-115).
} 
Pentas lakon Murwakala ${ }^{8}$ diiringi dengan nyanyian dari para sinden atau waranggana serta alunan musik dari seperangkat gamelan yang dimainkan oleh nayaga atau pengrawit. Upacara dipimpin oleh seorang dalang ruwat yang bertugas meruwat para sukěrta. Riasan dan busana khusus dikenakan oleh dalang ruwat, golongan sukěrta, sinden, dan nayaga. Sesaji (sajen) juga disiapkan. Kelengkapan-kelengkapan dalam upacara ini mengandung tujuan dan bermakna simbolis ${ }^{9}$.

Tradisi membersihkan atau mensucikan dosa, mala, klesa yang menimpa seseorang diduga telah dikenal sejak masa Singhasari-Majapahit. Tradisi upacara pembersihan diperkirakan telah ada sejak abad $15 \mathrm{M}$, yang dikuatkan dengan bukti artefak. Upacara ini tertulis dalam teks sastra yang dikenal dengan sebutan upacara lukat. Agar dapat bersatu dengan dewa atau işţadewata, seorang raja yang telah meninggal biasanya melalui upacara lukat. Abu jenazahnya diletakkan pada sebuah candi yang pada dindingnya dipahatkan hiasan relief bertemakan cerita lukat.

Artikel ini membahas ruwatan Murwakala sebagai sebuah tradisi lisan dan tulisan yang bersifat tangible dan intangible yang bersifat simbolis yang masih dilakukan dan dianggap relevan oleh masyarakat Jawa hingga saat ini. Teori ritus peralihan yang dikemukakan Arnold van Gennep dalam The Rites of Passage (1960:44) digunakan sebagai lensa untuk menganalisis upacara

\footnotetext{
${ }^{8}$ Lakon Murwakala ini tidak bersumber dari cerita India, lakon ini merupakan cerita carangan yang dikarang oleh dalang lokal, seperti dijelaskan oleh Zoetmulder, cerita ini merupakan cerita asli Jawa walaupun dewa- dewa dari mitologi India dan tokoh-tokoh Mahabharata masih muncul (1985: 540).

${ }^{9}$ Lewis Spence,"Suatu perbuatan keagamaan atau upacara, yang dengan bantuannya, manusia bekerja sama dengan dewa-dewa untuk kemajuan mereka atau untuk keuntungan keduanya“ (1947: 2).
}

ruwatan ini. Selain itu, artikel ini juga akan membahas peran dalang ruwat yang cukup unik karena ia tidak hanya berperan memainkan lakon wayang, tetapi ia juga menjadi bagian dari lakon tersebut.

Artikel ini didasarkan pada studi pustaka mengenai literatur kebudayaan Jawa, terutama mengenai Ruwatan Murwakala; pengamatan terhadap salah satu pelaksanaan upacara Ruwatan Murwakala di Surakarta, dan juga wawancara dengan para pelaku tradisi, antara lain dalang, keluarga sukerta, dan para sukerta.

\section{Asal usul Ruwatan Murwakala}

Cerita asal usul lakon Murwakala tercantum dalam teks naskah susastra pakem Lampahan Pedalangan. Teks ini menjadi pedoman para dalang yang akan melakonkan wayang kulit purwa dengan lakon Murwakala. Dalam Serat Pangroewatan, tjetjepenganipoen dalang ing padoesoenan ${ }^{10}$ R.Tanaja (1937) menyebutkan seorang dalang tua bernama Gandakarya yang bertempat tinggal di kota Surakarta menggunakan teks ini sebagai pedoman. Pakem Pangruwatan ini konon ini dibuat Bapak Satina, pada bulan puasa di hari Selasa pon, malam ke duapuluh satu, tahun pembuatan tidak diketahui ${ }^{11}$. Pakem Pedalangan yang lain ditulis oleh S.Probohardjono dan K.R.T. Mloyodipuro

\footnotetext{
10 Th.Pigeaud (1937), pedoman meruwat dalang desa di sekitar Surakarta, pakem ruwatan ini milik dalang Gandakarya yang usianya sudah 60 tahun sebelumnya, serta ditulis kembali oleh R.Tanaja (320).

${ }^{11}$ Di pakem tersebut, terdapat mantera-mantera yang dibaca oleh dalang ruwat. Mantra diawali dengan menyebut nama Allah swt, kemudian diikuti dengan bacaan mantera Caraka balik, Kudangan Kala, Sastra Pinedati, dan Sastra Pawenangan. Dalang membaca mantera Gembalageni saat memotong rambut anak yang diruwat. Mantra kemudian ditutup dengan doa nabi Adam dan doa mohon keselamatan pada Allah swt.
} 
$(1989)^{12}$, dan kemudian ditulis ulang oleh Mas'ud Thoyib Adiningrat (tt) ${ }^{13}$.

Lakon Murwakala adalah cerita simbolis yang berawal dari peristiwa perilaku pelanggaran norma yang dilakukan oleh Batara Guru terhadap istrinya, Dewi Uma. Tokoh-tokoh dalam lakon Murwakala adalah: Batara Guru ${ }^{14}$ Dewi Uma ${ }^{15}$,

\footnotetext{
${ }^{12}$ Pakem Pedalangan Lampahan Wayang Purwa, jilid 1(7-25)

${ }^{13}$ Murwakala Dan Ruwatan Gagrak Kraton Surakarta Hadiningrat (hal,13-32)

${ }^{14}$ Batara Guru atau Siwa pertama kali dituliskan dalam kitab Tantu Panggelaran ${ }^{14}$ yang berasal dari Jawa. Ia adalah seorang dewa yang bertempat tinggal di gunung
}

Mahameru / Mandara ${ }^{14}$ (India. Tempat ini diidentifikasikan sebagai gunung Semeru di Jawa(Pigeaud 1924: 96-7:Santiko 1992: 48) ${ }^{14}$. Batara Guru adalah penguasa di kahyangan yang dituliskan dalam naskah Pakem Pedalangan Lampahan Wayang Purwa. Lampahan Manik Maya (Jagad Ginelar) melukiskan ketika Hyang Maha Kawasa menciptakan dunia yang masih kosong, ketika itu ada suara keras yang memenuhi jagad, saat itulah muncul cahaya terang berbentuk bulat yang berputar-putar, sebutir telur menggantung dengan cepat dibawa oleh Hyang Maha Kawasa dengan kesaktiannya. Kulit telur itu berubah menjadi bumi dan langit, putih telurnya menjadi cahaya dan teja, kuning telurnya berubah menjadi manik dan maya (Probohardjono, 1989:

1).Versi lain dari terciptanya Batara Guru adalah cerita mengenai Dewi Rekatawati melahirkan anak berujud sebutir telur yang memancarkan cahaya terang. Sang Hyang Tunggal dengan kesaktiannya mengubah wujud telur tersebut. Kulit telur berubah wujud menjadi Hyang Maha Punggung sebagai anak sulung, putih telurnya menjadi Hyang Ismaya, ia dianggap sebagai anak nomor dua. Kuning telurnya menjadi Hyang Manikmaya yang dianggap sebagai anak bungsu.Sang Hyang Manikmaya mendapat tugas untuk mengepalai para dewa di kahyangan

${ }^{14}$ (Senawangi, 1999: 258-259). Pada pakem Pedalangan Lampahan Wayang Purwa, dalam Lampahan Lahiripun Batara Kala diceritakan bahwa Batara Guru adalah penguasa di Kahyangan Suralaya atau Jonggringsalak. Iamempunyai seorang istri bernama Bathari Uma (Probohardjono, 1989: 7-12: Tan Khoen Swie, 1954:7-8: Senawangi, 1999: 258-259).
Batara Kala ${ }^{16}$, Batara Naradha ${ }^{17}$, Batara Wisnu $^{18}$, Batara Brahma $^{19}$, Jaka Jatusmati, $^{20}$ dan Sapu jagad ${ }^{21}$

${ }^{15}$ Dewi Uma dalam lakon Murwakala adalah permaisuri dari Batara Guru.Salah satu anak dari Dewi Uma adalah Batara Kala. Di kalangan penganut Hindu aliran Saiwa, seperti ditulis dalam Kitab VayuPurăņa, Dewi Umadisebut dengan 'sakti'.Ia memiliki dua aspek yakni aspek santa atau saumya (tenang), dan aspek kroda atau raudra (dahsyat). DewiUma 'menjelma' menjadi dewidewi dengan aspek santa (saumya) sebagai Parvati (Uma), Sati, Gauri, dan sebagai aspek krodha adalah sebagai Durga, Kali, Karali, Kausiki, Candika dan lain sebagainya (Kumar 1974:231: dalam Santiko, 1992: 1, 297). Durgā, sebagai seorang dewi serta sebagai śảkti Śiwa dalam agama Hindu di India, selain digambarkan dengan dua aspeknya yaitu santa atau saumya (tenang), dan kroda atau raudra (dahsyat), dalam beberapa naskah ia juga digambarkan sebagai wujud yang cantik sekaligus menyeramkan ${ }^{15}$. Durgā dalam naskah Virataparwa (Mahabharata parwa IV) dilukiskan sangat cantik. Memiliki bentuk muka bagaikan bulan penuh, pinggul lebar dan buah dada besar, dan kulit kebiru-biruan bagaikan awan (Avalon, 1973:150). Durga dalam naskah Vişnudharmottaram, dilukiskansebagai sosok berkulit kuning keemasan dansangat cantik (Rao I/I 1968:67). Dalam naskah Vāmana Purāņa, keseluruhan ciri fisik Durgā yang cantik dilukiskan secara panjang lebar (Mukho padhyaya 1968:104, 109). Namun, dalam naskah Rūpamaņḍana Durgā digambarkan sebagai sosok yang menyeramkan. Ia berambut kuning, perut sangat cekung, memakai pakaian kulit harimau dan berhiaskan ular serta berkalung tengkorak. Kulitnya tubuhnya hitam dan ia mengendarai mayat (śavārūdha).Sosok Durgā inidikenal sebagai Caņdika atau muka yang menakutkan (krūrarūpā).Ia telah membinasakan Mahişāśuraserta Caņda dan Muņựa (Srivastava 1978:68-9). Durgā adalah sosok dewi dengan peranan penting dalam agama Hindu Saiwa dan Śakta di India. Ia memiliki beberapa aspek, sebagai penguasa tanaman dan kesuburan, serta sebagai penguasa penyakit menular seperti diuraikan dalam kitab Purāņa yaitu dalam Devi Māhātmya (11.4345:Agravala 1963: 139—41: Santiko, 1992: 199).

${ }^{16}$ Batara Kala dalam cerita wayang Murwakala merupakan salah-satu anak Batara Guru dengan Dewi Uma yang keberadaanya di dunia tidak diinginkan oleh ibunya, Dewi Uma. Semula ia pun tidak diakui oleh ayahnya, Batara Guru karena ia berwujud raksasa. Sebelum memiliki nama, ia 
disebut Kendhang Gumluntung atau kamasalah.

Saat Batara Guru mengakuinya sebagai anak, ia pun diberi nama Batara Kala yang berarti

Dewanyawaktu atau dewa yang berjalan seharihari). Kehadiran Batara Kala dalam cerita-cerita Jawa Kuna dan Pakem pedalangan adalah sebagai berikut: Batara Kala dalam Kitab Tantu Panggelaran dilukiskan mendapat tugas dari Batara Guru sebagai penjaga gapura di sebelah baratbersama raksasa Anungkala, gapura tersebut terletak di Pengawan. Gapura sebelah timur di Purnajiwa dijaga oleh sang hyang Gana. Gapura disebelah selatan yang terletak di Padang dijaga oleh Resi Anggasti. Gapura disebelah utara dijaga oleh Bhatari Gori (Pigeaud 1924: 96-7:Santiko 1992: 48)' Dalam Pakem Pedalangan, 'Lampahan LahiripunBatara Kala’ ia juga diceritakan sebagai anak Batara Guru dan Dewi Uma yang keberadaannya tidak direncanakan dan tak diduga. Batara Kala tercipta dari kama benih (sperma/air mani) Batara Guru yang keinginnannya tidak tersalurkan secara semestinya, dan jatuh ke samudra ( Probohardjono, 1989:7-12; Mudaningrat 1975: 24-25).

${ }^{17}$ Batara Naradha adalah saudara tertua Batara Guru. Di dalam cerita MurwakalaBatara Naradha dilukiskan sebagai sosok kakak yang bijaksana dan selalu mengingatkan Batara Guru. Ia menunjukkan pada Batara Guru bahwa perbuatannya di masa lalu telah mengakibatkan lahirnya Batara Kala.

${ }^{18}$ Batara Wisnu mendapat tugas dari Batara Naradha untuk turun ke bumi dan menjadi Dalang Kand̦abuwana dalam upaya memberhentikaan perilaku Batara Kala yang akan memangsa manusia di bumi. D,alang Kand̦abuwana mempunyai pengertian dalang artinya orang yang memainkan wayang, kandha berarti ceritera, criyos, pangandika, dikandani (Poerwadarminta 1939: 185) buwana adalah jagad atau tanah yang luas (Poerwadarminta 1939: 55). D, palang Kand̦abuwana adalah simbol dari keberadaan Yang Maha Kuasa pada saat Jathusmati keluar dari kelir atau panggung wayang. Dalang Kandabhuwanaadalah perwujudan dari Batara Wisnu yang mendapat tugas dari Batara Guru untuk meruwat sukerta dalam cerita lakon Murwakala.(kutipan:BS).

${ }^{19}$ Batara Brahma adalah putra kedua Batara Guru dalam bahasa pedalangan wayang kulit purwa lebih sering diucapkan Brahma. Brahma bertempat tinggal di kahyangan Duksinageni atau disebut juga Hargadahana atau Argadahana (Harsrinuksmo, 1999:331). Tetapi dalam lakon Murwakala, Brahma
Alkisah, Batara Guru sedang melakukan perjalanan melanglang buana bersama istrinya dengan mengendarai lembu Andini. Menjelang senja, Batara Guru melakukan hubungan suami istri dengan Dewi Uma. Sang Dewi sebenarnya kurang berkenan dengan hal itu. Namun, perbuatan itu telah mengakibatkan lahirnya seorang bayi laki-laki berwujud raksasa. Batara Guru tidak mengakui bayi tersebut dan tidak memberinya nama. Si bayi berniat mencari orang tuanya. Ia bertapa sepanjang waktu agar niatnya bertemu orang tuanya terpenuhi. Kegiatan tapa si bayi sangat kuat hingga mengguncang khayangan, tempat tinggal Batara Guru dan Dewi Uma. Batara Naradha mencari

bertempat tinggal di Kahyangan Marchukunda Manik atau Marchukunda (KMS:5-BS:4). Dalam lakon Murwakala BataraBrahma diminta oleh Narada untuk membantunya dan menjelma ke dunia menjadi panggender (KMS:21-BS:23)

${ }^{20}$ Jaka Jatusmati adalah penggambaran salah satu tokoh dalam lakon Murwakala. Jathusmempunyai arti sangat dekat danmati artinya meninggal (Poerwadarminta, 1939:83).Jaka Jathusmati adalah penggambaran sosok seorang anak (sukérta). Ia terlahir ontang-anting(tanpa saudara kandung)dari Nyai Randa Sumawidari desa Ngandong Dadapan.Setelah melaksanakan perintah ibunya berendam di danau Madirda namanya berubah menjadi Jatirasa atau Rasa Sinawur.

${ }^{21}$ Sapu Jagat merupakan perwujudan dari Batara Bayu adalah salah satu tokoh dalam cerita Murwakala yang diberi tugas untuk turun ke bumi dan menjelma menjadi Sapu Jagat. Ia juga salahsatu anak dari Batara Guru yang dalam cerita Murwakala diberi tugas oleh Narada untuk turun ke bumi dan menghalangi perbuatan BataraKala dalam mencari makanannya yaitu anak-anak dari golongan sukérta. BataraBayu dalam lakon pedalangan adalah salah satu anak dari Sang Hyang Jagatnata dengan Dewi Umayi (Murdaningrat, 1975: 24) ${ }^{21}$. Dalam lakon Murwakala Sapu jagad atau BapaTuna adalah anak tunggal dari Nyai Randa Sumawi yang sudah tidak mempunyai bapak, yang tinggal di desa Kraeng Pradesan Andong Dadapan. Ia dikejar-kejar oleh Batara Kala karena sebagai salah satu mangsanya. 
pertapa yang telah mengguncang Kahyangan, yang ternyata si bayi berwujud raksasa. Si bayi kemudian dipanggil ke istana Marcukundha Manik di Kahyangan untuk bertemu dengan Batara Guru yang ternyata ayah kandungnya. Si bayi minta diberi nama, diberi makanan, diberi pakaian dan diberi tempat tinggal. Batara Guru memberinya nama: Batara Kala. Batara Guru juga memberinya pakaian dan makanan. Batara Guru bersabda:

"manusia yang memang dapat menjadi makananmu, yaitu ada 3 macam dosa manusia yaitu :pertama dosa karena ucapan, kedua dosa karena kelahirannya sebagai golongan sukerta, ketiga dosa karena kehendak Nya yang menjadi bawaan anak yang baru lahir di dunia, itu mutlak menjadi makanan Kala.”

Sejak saat itu, makanan Batara Kala adalah segolongan sukérta. Sejak itu, Batara Kala pergi dari kayangan ke dunia untuk mencari makan berupa manusia yang termasuk golongan sukěrta. Mengingat Batara Kala akan memakan semua sukerta, Batara Guru segera meminta Kanekaputra atau Batara Naradha untuk turun dan menyamar ke dunia bersama Batara Wisnu. Mereka diminta oleh Batara Guru untuk menjadi Dalang Kandhabuwana. Tugas mereka adalah meruwat manusia agar tidak menjadi makanan Batara Kala.

\section{Prosesi ruwatan}

Prosesi ruwatan yang dijadikan contoh kasus dalam artikel ini adalah prosesi ruwatan anak perempuan Agus Purwanto yang diselenggara-kan pada 8 September 2012. Agus Purwanto adalah seorang sarjana seni yang bekerja sebagai dosen di salah satu perguruan tinggi seni di Surakarta. Ia dan istrinya memiliki dua orang anak perempuan yang berumur lima tahun. Anak pertama yang bernama Rara Arum dan anak kedua bernama Haranu Prabaningrat. Anak pertama sering sakitsakitan, dan anak kedua sering sekali mengalami kecelakaan, salah satunya tersiram air panas. Kejadian buruk yang sering menimpa kedua anaknya membuat Agus dan istrinya merasa khawatir. Di dalam kepercayaan Jawa, dua orang anak perempuan disebut kembar sepasang dan merupakan salah satu golongan sukerta ${ }^{22}$. Ia dan istrinya pun kemudian memutuskan untuk meruwat anak mereka.

Agus menghubungi Dalang Budi Suwarto yang kebetulan juga seorang dosen bergelar Doktor di sebuah perguruan tinggi Negeri di Solo yang terkenal sebagai dalang ruwat. Agus mengemukakan keinginannya pada Dalang Budi untuk melaksanakan upacara ruwatan bagi kedua putrinya. Selain itu, ia juga menyampaikan keinginan untuk mempunyai anak laki-laki.

Dalang Budi kemudian mencari waktu yang tepat bagi pelaksanaan upacara ruwatan Murwakala bagi kedua anak Agus. Pelaksanaan upacara ruwatan disesuaikan dengan perhitungan waktu yang selama ini digunakan oleh masyarakat Jawa, yaitu

\footnotetext{
${ }^{22}$ Golongan sukěrta menurut penuturan Dalang ruwat Budi Suwarto, sesuai dengan lakon Murwakala, kriterianya disebutkan dalam dialog tanya jawab antara Batara Guru dan Batara Kala. Terdapat tiga macam kriteria yang termasuk dalam golongan sukěrta sebagai jatah makan Batara Kala yaitu: 1) manusia yang membawa dosa karena kelahirannya, 2) manusia yang memiliki dosa karena perbuatannya; 3) dosa karena sudah kehendak Nya. Kriteria pertama mutlak menjadi makanan Kala, yaitu :1) Ontang Anting atau seorang anak laki-laki yang terlahir tanpa saudara kandung, 2)unting - unting atau seorang anak perempuan yang terlahir tanpa saudara kandung, 3) uger uger lawing atau dua anak laki-laki semua, 4) kembang sepasang ataudua anak perempuan , 5) Kedhana-Kedhini atau dua anak laki-laki dan perempuan, 6) Kedhini-Kedhanaatau dua anak, perempuan, 7) Pandawa atau lima laki-laki semua, 8) Ngayomiatau lima anak perempuan semua, 9) Madhangake atau lima anak, empat laki laki dan satu perempuan, 10) apil-apilyaitu lima anak; empat perempuan satu laki-laki, 11) Jisim Lumaku. : seorang anak yang berjalan sendiri saat tengah hari sendirian. 12). Ontang-anting luminting tunggaking aren : orang yang hidup sebatang kara.
} 
dengan melihat waktu kelahiran dari kedua anak-anak perempuannya tersebut. Anak pertama yang lahir pada hari Senin pon 23 Oktober 2004 dan anak kedua lahir pada Jumat Kliwon 18 Maret 2007. Sesuai perhitungan Dalang, waktu penyelenggaraan upacara ruwatan yang terbaik bagi kedua anak tersebut jatuh hari Selasa Kliwon. Di dalam kalender Masehi, perhitungan itu jatuh pada tanggal 8 September 2012. Pada tanggal tersebut, waktu atau sangat penyelenggaraan upacara ruwatan antara 9.00 pagi -sampai jam 15.00 sore hari. Puncak waktu atau sangat jatuh pada jam 12 siang, saat Batara Kala mulai mencari mangsa anak-anak golongan sukěrta.

Pada hari pelaksanaan, ritual dimulai dengan menyiapkan aneka perlengkapan, yaitu seperangkat wayang kulit dengan tokoh-tokoh utama yang berperan dalam cerita Murwakala. Selain itu, sesaji atau sajen juga disiapkan. Piranti inti bagi sesaji ruwatan berupa makanan, tumbuhtumbuhan, alat pertanian untuk laki-laki dan perempuan, satu pasang binatang yang hidup di air, tujuh pasang aneka jenis unggas, bokor berisi air dari tujuh sumber (sumur), sekar setaman yaitu bunga aneka warna, gunting untuk memotong rambut, klasa (tikar), bantal, dan payung, pengilon (cermin), pupur (bedak), jungkat suri (sisir bergigi rapat), sapu sada mawi suh selaka (sapu lidi), anglo (tungku tanah liat), obong (dupa) ${ }^{23}$.

Dalang Ruwat bertugas memimpin seluruh prosesi Ruwatan Murwakala. Seorang dalang ruwat diperkenankan meruwat apabila ia adalah keturunan seorang dalang, telah menikah dan mempunyai anak serta telah memiliki anak yang menikah. Sebelum meruwat, seorang dalang harus melakukan puasa mutih yaitu hanya makan nasi putih dan air putih saja selama 40 hari. Setelah selesai puasa, ia

\footnotetext{
${ }^{23}$ Wawancara dengan pembuat sesaji/sajen, pada tanggal 10 November 2012 di Surakarta.
}

akan menjalani upacara pengesahan sebagai dalang ruwat oleh para leluhurnya dan dalang-dalang tua sebanyak tujuh orang (kakek, kakek buyut dan kerabat) sebagai dalang ruwat ${ }^{24}$.

Dalang ruwat adalah orang biasa tetapi ia dipercaya oleh masyarakat karena dianggap memiliki kualifikasi keimanan tinggi, kecakapan, dan mempunyai banyak pengalaman untuk melakukan ritual khususnya Ruwatan Murwakala. Dalang ruwat mempunyai kemampuan rohaniah yang membuatnya mampu memimpin upacara. Ia mempunyai peran sosial dan tingkat kekuasaan yang tertinggi karena memiliki otoritas untuk mensucikan golongan sukérta. Ia dengan cara dan doanya dapat berhubungan dengan Tuhan YME sebagai wakil dari kedua orang tua sukérta serta dapat menyelamatkan sukérta dari mangsa Batara Kala serta mengentaskan golongan sukérta dan kembali menjadi suci. Oleh karena tugas beratnya, sebelum melaksanakan tugasnya biasanya dalang ruwat akan mempersiapkan diri secara mental dan psikologis agar dapat melaksanakan ritual dengan lancar sampai akhir.

Orang yang diruwat atau orang sukerta mengenakan baju putih (kopohan) selama berlangsungnya acara ruwatan. Sebelum upacara dimulai, mereka melakukan sungkem pada kedua orang tua pertanda minta ijin mengikuti ruwatan. Di dalam pelaksanaan upacara ruwatan Murwakala, dalang akan menceritakan lakon Murwakala. Adegan dimulai dengan percakapan antara Batara Narada dan Batara Guru. Berikut ini cuplikan transkripsi salah satu dialog dalam lakon Muwakala yang telah diterjemahkan dalam Bahasa Indonesia. Di dalam lakon itu, Batara Narada (NRD) mengingatkan Batara Guru (BG) atas akibat dari

\footnotetext{
${ }^{24}$ Wawancara dengan seorwang dalang ruwat pada tanggal 8 September 2012 di Surakarta.
} 
perbuatan yang ia lakukan bersama istrinya, Dewi Uma.

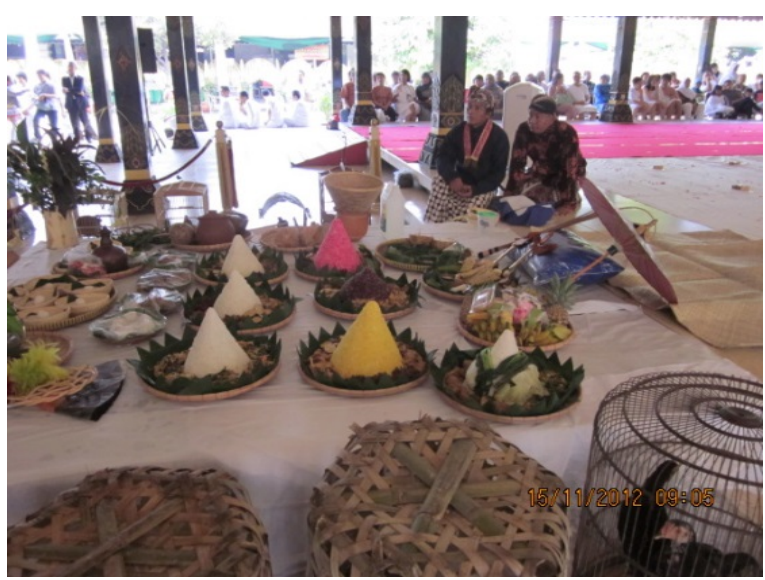

Sesaji untuk pelengkap ruwatan

Dokumentasi Foto: Lies Mariani

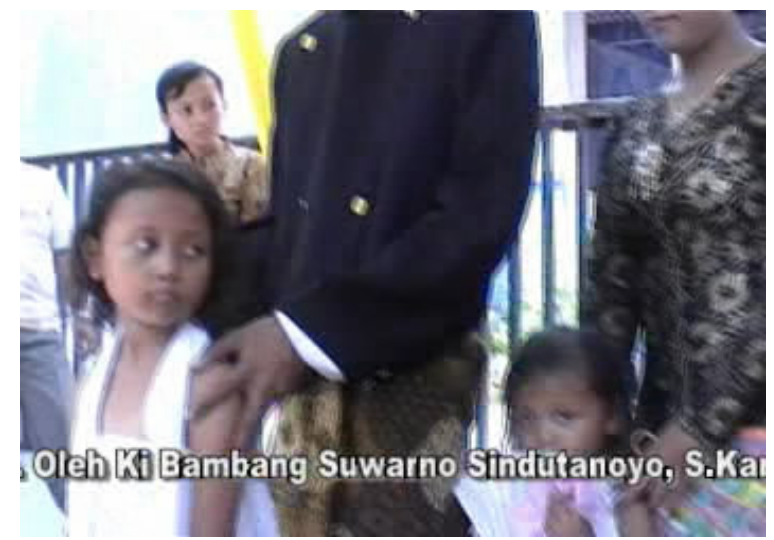

Anak sukerta kembang sepasang yang hendak diruwat. Dokumentasi Lies Mariani

Batara Narada:

Adhiguru, apakah Adhiguru lupa, bahwa adanya huru-hara di kahyangan yang Adhiguru maksud sebenarnya bermula dari kepulangan Adhiguru setelah menjelajahi bumi, baik melalui sisi timur, sisi selatan, sisi utara dan seterusnya sisi barat. Pada saat itu adalah saat waktunya menjelang petang, cahaya dari Hyang Bagaskara memancarkan waktu akan berganti, cahaya yang paling kuat dan tajam yang melintas pada pergantian hari, menyiratkan prabawa cahaya diwajah Dewi Uma yang mendapatkan sinar cahaya, Adhiguru bersama didekatnya, mohon maaf Adhiguru, saat itu muncul keinginan yang tidak tersampaikan Adhiguru dan sebagai priya yang ingin melakukan hubungan satu rasa, tetapi istri paduka Bathari Uma memberi tanda tidak menginginkannya. Kama di Ganjutalaya. Kama telah jatuh ke samudera.

\section{Batara Guru:}

Saya mohon bantuan kepada kakang Narada bagaimana caranya untuk membatasi perbuatan Batara Kala mencari makan di dunia dan bagaimana untuk membatasi perilaku Batara Kala untuk mencari makan di dunia.

\section{Batara Narada:}

Hari ini, untuk diketahui ya Nak, bahwa untuk dapat membatasi tingkah laku Batara Kala di Madyapada, aku diperintahkan untuk menjadi pengawalnya dalang yang akan menjalankan proses peruwatan, meruwat sukěrta-nya manusia, karena banyak sekali sukěrta yang akan dijadikan makanan Batara Kala, yaitu orang yang memiliki dosa sukěrta yakni; orang yang memiliki dosa sarik yaitu dosa karena tinggal di tempat baru yang belum diruwat, tanah yang miring. Sang Hyang Jagad Giripati memberikan jatah makanan Batara Kala adalah orang yang memiliki dosa pengucap-ucap. Manusia dengan dosa pengucap-ucap yang harus jadi makanan Kala adalah anak tunggal laki laki atau disebut ontang-anting, anak tunggal perempuan disebut unting-unting, dua anak laki laki semua atau disebut uger-uger lawang, dua anak perempuan semua atau disebut kembang sepasang. Maka dari itu, untuk mengatasi ini akan segera diciptakan benih dalang pertama yang harus tumbuh dari watak kedewataan, namun yang bisa menjadi dalang ini hanya Jawata yang disebut Nata Bawana (pemelihara alam), permintaan Sang Hyang Jagad Giri Nata hanya kamu Wisnu, Wisnu kamu lah yang dipercaya mengemban tugas ini sebagai dalang permulaan.

Pada adegan selanjutnya, dikisahkan cerita mengenai seorang manusia yang bernama Jatusmati. Ia anak lelaki satu-satunya dari seorang janda yang bernama Nyai Randha Sumawi. Karakter Jatusmuti diceritakan mewakili golongan sukerta ontang-anting. Ia rawan menjadi mangsa Batara Kala sehingga ibunya memintanya untuk diruwat. Sumawi menyuruh anaknya untuk berendam di Telaga Madirdha agar terhindar dari bahaya. 
Inti acara ruwatan dimulai saat sang dalang ruwat membacakan mantera yang ditujukan agar Batara Kala mengurungkan niatnya memakan anak-anak golongan sukěrta. Mantera-mantera yang dibaca oleh Dalang ruwat sebenarnya adalah manteramantera milik Batara Guru, ayah dari Batara Kala. Dikisahkan bahwa Batara Guru berpesan pada putranya bahwa saat ia mendengar matera itu dibacakan, ia mesti yakin bahwa siapapun yang membaca mantera-mantera itu pastilah saudara tua ayahnya. Dengan demikian Batara Kala harus menghormati si pembaca mantera. Batara Kala akan luluh hatinya setelah mendengar mantera-mantera tersebut diperdengarkan. Ia akan patuh serta mengikuti perintah si pembaca mantera. Di dalam lakon Murwakala, adegan luluhnya hati Batara Kala digambarkan dalam dialog antara Dalang Ruwat dan Batara Kala, saat sang dalang berupaya membujuk Batara Kala untuk kembali ke asalnya di Nusa Barong.

Dalang:

Sekiranya Sang Hyang Kala mendengarkan dengan khusuk dan khidmat, niscaya tidak terasa air matamu akan menetes dalam alunan bacaan mantra atas sastra pusaka kedewataan

Bara Kala:

Ya ki dhalang, aku menerima dengan kerendahan hati, bahwa ki dhalang lebih tua dari aku, sekarang apa yang akan ki dhalang perbuat kepada saya?

Dalang:

Kala, kiranya kamu dengan ikhlas mau menuruti ucapanku, mohon agar kamu pergi dari tempat ini, dari rumah Agus Purwanto di Jalan Puncak Solo no 8. Juga dengan semua pengikutmu dan pasangan hidupmu

Batara Kala :

Ya Bapa, aku menurut atas titah dan perintahnya, mohon kiranya ki dhalang berkenan menembangkan bagiku santi kukus, sebagai tanda perjalanan pergi dari tempat ini.

Setelah dialog selesai dalang ruwat menarik kupat luar dan menyebar beras kuning sebagai pertanda perginya Batar Kala.

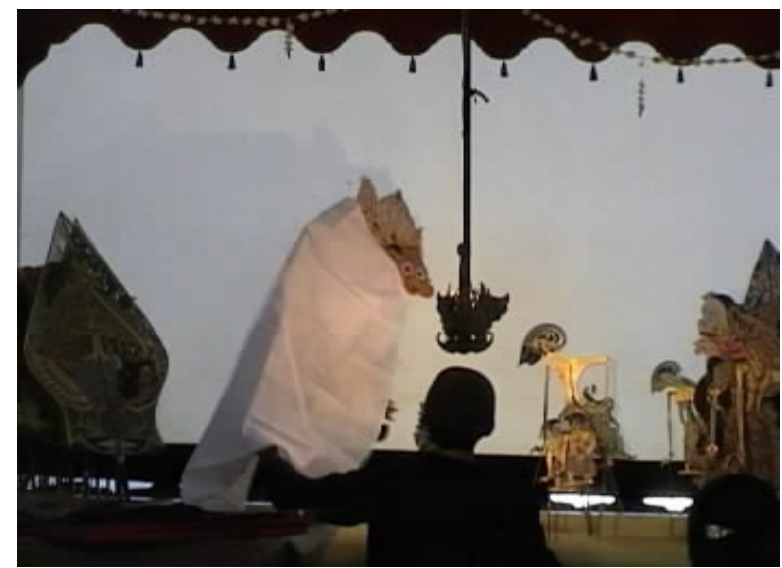

Dalang Kandhabuwana saat membacakan manteramanteranya kepada Batara Kala. (Foto dokumentasi Lies Mariani)

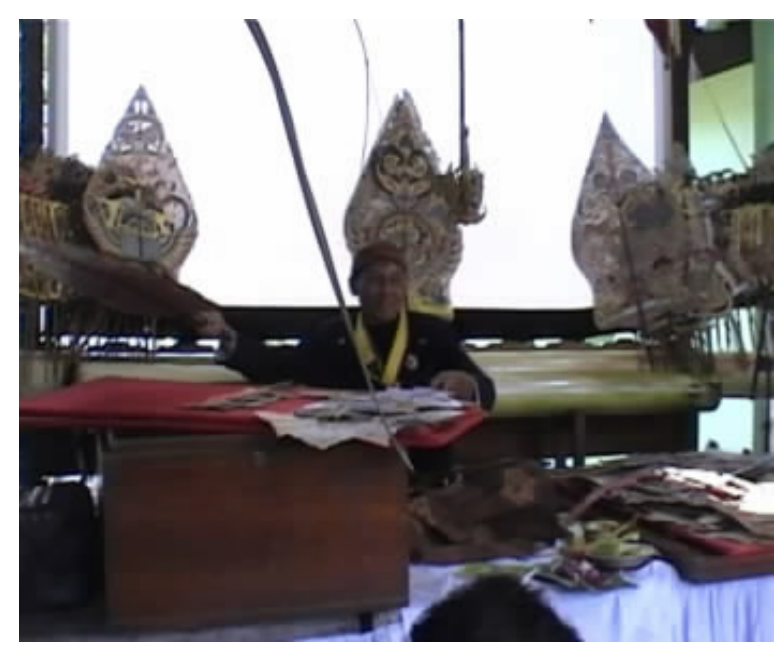

Dalang ruwat setelah selesai melakonkan cerita Murwakala kemudian menarik kupat luar dan menyebar beras kuning. (Foto dokumentasi Lies Mariani)

Dalang ruwat melanjutkan ritual dengan memotong rambut anak-anak sukerta dan memandikan mereka dengan air yang diambil dari tujuh sumber atau tujuh sumur yang dilengkapi dengan bunga setaman (bunga dengan tujuh macam bungabungaan). Setelah itu, dalang menyerahkan para mantan sukěrta dikembalikan kepada orang tuanya. Dengan demikian upacara ruwatan yang berlangsung sekitar 90 menit pun berakhir.

Agus Purwanto menyatakan bahwa setelah ruwatan bagi putrinya dilakukan, beban 
psikologis yang selama ini terasa berat terasa hilang. Menurutnya, kedua anak perempuannya sudah sehat dan jarang sakit setelah diruwat. Anak kedua juga sudah tidak pernah mengalami kecelakaan seperti sebelumnya. Selain itu, dua tahun setelah upacara ruwatan, ia dan istrinya telah dikaruniai seorang anak laki-laki, sesuai keinginannya sebelum ruwatan untuk anaknya dilaksanakan. Agus merasa bahwa ruwatan yang ia lakukan untuk anaknya telah berdampak baik bagi kehidupan keluarganya.

\section{Pembahasan}

Arnold van Gennep (1977) dalam Rites of Passage menjelaskan bahwa manusia sejak lahir hingga mati mengalami perubahanperubahan biologis yang berdampak pada status sosial budayanya. Situasi di mana seorang manusia berada pada masa peralihan menuju tahap biologis selanjutnya, disebut masa liminal. Masa ini sangat berbahaya karena ketidakjelasan status sosial budaya seorang manusia. Keberadaan manusia pada situasi ini berdampak pada jiwanya dan dapat menimbulkan krisis mental. Oleh karena itu, setiap manusia yang berada pada tahap ini perlu mengikuti upacara inisiasi untuk menandai dan mengantarkan peralihannya ke tahap kehidupan yang baru dan yang lebih stabil.

Manusia akan mengalami proses liminal, inisiasi, dan stabil ini sepanjang daur hidupnya, sehingga digambarkan sebagai sebuah siklus melingkar sepanjang hidup. Gennep (1977) juga menyebut bahwa upacara terkait daur hidup manusia secara umum memiliki 3 tahapan, yaitu separations atau rites of separation (perpisahan) pada tahap pertama, marge atau rites of liminal (peralihan) pada tahap kedua, dan aggregation atau rites of incorporation (pemulihan) pada tahap ketiga. Proses ini berlangsung sepanjang hidup sehingga meski telah diupacarai, manusia tetap akan menemui dan mengalami masa liminal berikutnya sehingga ia perlu diupacarai sepanjang daur hidupnya. Proses itu dapat digambarkan sebagai diagram melingkar sebagai berikut:

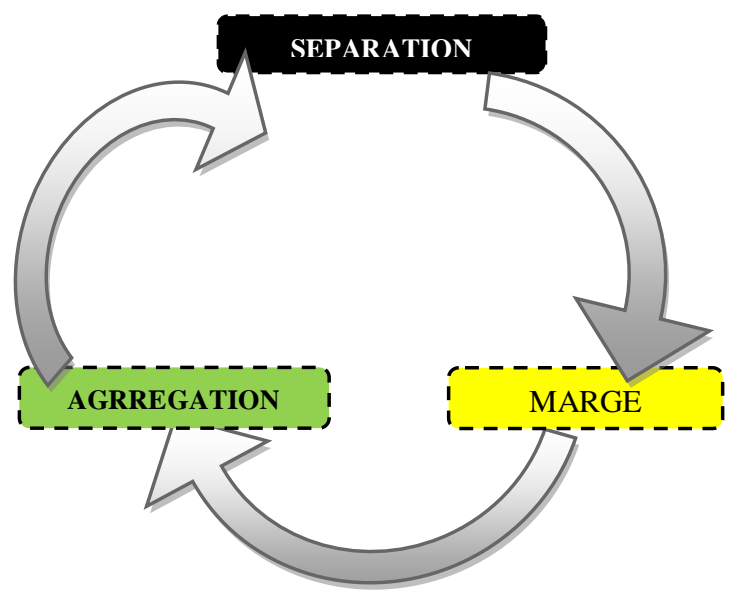

Masyarakat Jawa juga memiliki ritus peralihan seperti yang dikemukakan Gennep. Sejak sebelum seorang manusia lahir, hingga mati, aneka ritus diterapkan padanya. Misal, ritus tujuh bulanan atau tingkeban pada wanita hamil saat kehamilan menginjak umur tujuh bulan. Ritus ini menandai kemunculan calon manusia. Pada saat bersamaan, ritus itu juga menandai peralihan seorang manusia perempuan untuk menjadis eorang ibu. Contoh lain adalah ritus peralihan di Jawa adalah upacara kelahiran bayi yang meliputi upacara puputan dan cukuran (muncukur rambut) upacara turun tanah tedak siten, upacara khitanan bagi anak laki-laki maupun perempuan, upacara perkawinan, hingga upacara kematian.

Upacara Ruwatan Murwakala adalah bagian dari ritus peralihan tetapi memiliki karakteristik yang agak berbeda. Diagram Van Gennep berbentuk lingkaran menggambarkan kesinambungan proses peralihan sepanjang hidup manusia. Sedangkan ruwatan hanya menggambarkan salah satu bagian saja dari kisah hidup manusia di dunia. Ritus Ruwatan Murwakala hanya dilakukan satu kali sepanjang hidup dan bertujuan untuk 
menghilangkan liminalitas seorang manusia secara permanen. Namun demikian, prosesi ruwatan tetap mengikuti konsep tiga tahapan upacara yang disebut oleh Van Gennep yaitu:

(1) proses perpisahan (separation) sukěrta berada dalam kondisi tidak normal karena sebagai mangsa Batara Kala; (2) proses pengentasan sukěrta dengan kondisi kotor menuju ke kondisi suci kembali dengan cara mengikuti upacara; (3) proses pemulihan dimana sukérta sesudah diruwat akan terbebas dan kembali menjadi 'suci' serta akan terhindar dari mangsa Batara Kala. Proses ini dapat digambarkan dalam diagram garis lurus sebagai berikut:

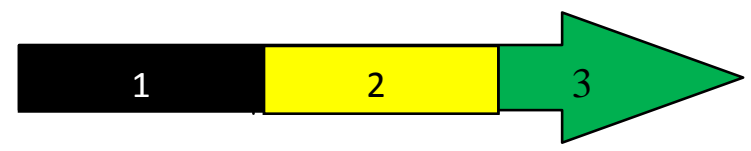

1: perpisahan (separation): tokoh sukěrta sebagai kondisi/situasi 'kotor' atau berdosa'.

2: peralihan (marge): mengentaskan tokoh sukěrta untuk disucikan kembali, dengan menjalani upacara RM.

3: integrasi kembali (agregation): suatu keadaan sukěrta sesudah diruwat akan terbebas dari mangsa Bathara Kala. Dengan kondisi 'suci' kembali

Kotak berwarna hitam adalah gambaran dari tahap pertama dalam ritus; kotak kedua berwarna kuning menggambarkan proses pengentasan sukěrta dari kondisi yang kotor upacara RM, dan kotak ketiga berwarna hijau menggambarkan kondisi sukěrta yang kembali ke kondisi suci.

Pada tahap pertama, para sukěrta dianggap sedang berada dalam kondisi kotor' atau berdosa'. Bagian dari prosesi ruwatan yang masuk dalam kotak ini adalah persiapan perpisahan dengan kondisi kotor, penyiapan sesaji disiapkan, dan pemilihan waktu dan tempat pelaksanaan ruwatan. Para Sukěrta berkumpul di tempat upacara dengan mengenakan pakaian putih (kopohan). Para sukěrta melakukan sungkem kepada kedua orang tua mereka. Setelah sungkeman selesai, dalang pun memulai upacara ruwatan.
Tahap ini adalah tahap separasi atau perpisahan (separation) atau (rites of separation) atau ritus praliminal (preliminal rites) yang menggambarkan tahapan manusia melepaskan diri dari kedudukannya semula. Pelaksanaan 'ritus' atau' upacara' biasanya terdiri dari tindakan-tindakan yang melambangkan 'perpisahan'. 'Ritus' yang mengandung makna seolah individu yang bersangkutan 'dibunuh' atau dibuang seperti 'tidak ada' lagi. Ritus ini dimaksudkan untuk membebaskan seseorang atau jabang bayi, bocah bajang dari 'pengaruh jahat' atau 'kutukan'. Seseorang yang akan diruwat dianggap dalam situasi dan kondisi 'kotor', disebut wong sukěrta. Oleh karena itu diupayakan untuk disucikan dengan jalan inisiasi, dengan cara 'diasingkan atau dibuang'.

Situasi golongan wong sukěrta' di dalam lakon Murwakala digambarkan dengan munculnya Batara Kala sebagai anak dewa yang kehadirannya tidak diinginkan oleh kedua orang tuanya (Batara Guru dan Dewi Uma). Setelah menjelang remaja, ia mencari tahu siapa kedua orang tuanya. Terpisahnya Batara Kala dengan orang tuanya melambangkan terpisahnya anak dan orang tuanya dan juga dari lingkungan sosial di dalam tahap kehidupan awalnya. Kisah manusia sukerta diwakili oleh kisah Jatusmati, anak yatim dari seorang janda yang menetap di Desa Karang Pradesan. Jatusmati disuruh ibunya untuk pergi ke danau Madirda untuk membersihkan dan mensucikan dirinya. Tahap kedua (marge) adalah pagelaran wayang yang dilakukan oleh dalang. Tahap ini adalah inti dari ruwatan yang bertujuan mengentaskan tokoh sukěrta untuk disucikan kembali. Upacara berlangsung selama 90 menit, mulai dari awal prosesi pementasan Lakon Murwakala selesai sampai tancep kayon. Pada saat pagelaran selesai, dalang menarik kupat luar dan menyebar beras kuning serta melepas merpati putih. 
Tahap ketiga yang melambangkan integrasi kembali (agregation) yang ditandai dengan adegan potong rambut sukerta dan siraman dengan air dari tujuh sumber mata air atau sumur. Pada tahap ini para sukerta digambarkan kembali suci dan terbebas dari mangsa Batara Kala. Menurut penuturan Dalang ruwatan di Surakarta, Budi Suwarto, lakon Murwakala pada dasarnya menyimbolkan kehendak Tuhan Yang Maha Esa dalam upaya menyelamatkan manusia.

Proses penyelamatan ini dilakukan dengan cara ruwatan dan dibantu oleh dhalang kawitan yang berperan sebagai mediator, yaitu Dalang Kandhabuwana. Pertemuan Batara Kala dengan Dalang Kandhabuwana dalam lakon Murwakala merupakan simbol dari awal mula proses pensucian manusia sukerta. Dialog antara Dalang Kandhabuwana dengan Batara Kala adalah substansi ruwat itu sendiri. Hal ini menggambarkan situasi manusia yang sedang berdialog dengan Sang Khalik melalui Dhalang kawitan atau Dalang Kandabuwana. Lakon Murwakala menggambarkan nilai dan hakikat kehidupan manusia yang berisi hubungan manusia dengan Tuhan, hubungan manusia dengan sesamanya, hubungan manusia dengan alam semesta dan lingkungannya, serta hubungan manusia dengan dirinya sendiri.

Dalang ruwat sebagai pemimpin ritus merupakan tokoh yang memiliki peran penting. Ia dmewakili orang tua golongan sukérta untuk memohon bantuan kepada Tuhan YME untuk menyelamatkan golongan sukérta dari mangsa Batara Kala, serta mengentaskan golongan sukérta kembali menjadi suci. Kedudukan dalang sebagai orang terhormat dan dihormati dalam masyarakat pendukungnya, dianggap mampu menjadi mediator antara manusia dan Tuhan YME bagi terwujudnya tertib kosmos yang ditandai dengan adanya hubungan yang harmonis antara manusia, kekuatan gaib dan alam semesta.

\section{Kesimpulan}

Ritus Ruwatan Murwakala adalah salah satu tradisi yang masih dianggap sakral untuk meruwat golongan sukérta di Surakarta (pusat budaya). Ritus ini merupakan salah satu kearifan lokal yang sampai sekarang masih cukup relevan untuk dilaksanakan, mengingat ritus tersebut merupakan intangible cultural heritage yang dimiliki oleh bangsa Indonesia serta perlu untuk dilindungi dan dilestarikan.

Ritus ini adalah bagian dari ritus peralihan yang mengikuti tiga tahapan peralihan sesuai dengan teori Van Gennep tetapi dengan karakteristik yang agak berbeda. Ritus peralihan Van Gennep dilakukan sepanjang hidup karena tidak mampu menangkal bahaya-bahaya selanjutnya yang muncul akibat perubahan biologis, sedangkan ritus Ruwatan Murwakal hanya dilakukan satu kali dan sanggup menangkal bahaya sepanjang hidup. Ritus Ruwatan Murwakala menggambarkan pandangan mistis masyarakat Jawa, yaitu adanya pemahaman bahwa Dalang ruwat merupakan penghubung antara manusia dengan Tuhan YME serta antara manusia dengan sesamanya dan manusia dengan alam semesta. Dalang ruwat dianggap menguasai pengetahuan gaib, serta mampu berhubungan dengan leluhurnya, yaitu dengan kekuatan-kekuatan yang tidak tampak tetapi masih menguasai kehidupan masyarakat secara gaib. Dalang ruwat juga merupakan perantara manusia dengan Tuhan YME untuk memohon karunianya serta keselamatan di dunia.

Keinginan Agus Purwanto untuk meruwat ke dua putrinya yang termasuk golongan sukěrta kembang sepasang ini merupakan salah satu bukti betapa ruwatan masih dianggap sebagai ritus yang relevan bagi masyarakat Jawa masa kini. Agus memiliki tingkat pendidikan yang cukup 
tinggi sebagai akademisi, tetap masih bersedia untuk melakukan ritus. Keluarga Agus Purwanto ini merupakan salah satu penggambaran dari salah satu karakteristik orang Jawa yang masih mempunyai suatu keyakinan serta kepercayaan dengan tradisinya yaitu ritual RM.

\section{Daftar Pustaka}

Atmodjo.K Sukarto. 1990. Ruwatan Dalam Pewayangan. dalam Catatan Singkat Ruwatan Di Bali. (seminarruwatan, 1 september 1990). Lembaga Javanologi. Yayasan Ilmu Pengetahuan dan Kebudayaan Panunggalan Bekerjasama dengan Balai Kajian Sejarah dan Nilai Tradisional.Yogyakarta.

Finnegan, Ruth. 1977. Oral Poetry. Its Nature, Significance and Social Context. London: Cambridge University Press.

Finnegan, Ruth . 1977. Oral Poetry. Bloomington and Indianapolis: First Midland Book Edition.

Finnegan, Ruth . 1992. Oral Tradition and The Verbal Art: a Guide to Research Practice.London: Routledge.

Finnegan, Ruth. 2012 Oral Literature In Africa. World Oral Literature Series: Volume 1. Open Book Publishers CIC Ltd. United Kingdom.

Gennep, Arnold van.1960. The Rites of Passage, translated by Monika B Visedom Gabrielle L. Caffee, London: Routledge and Kegan Paul.

Groenendael, Clara van. Victoria M. 1985 The Dalang Behind The Wayang.Dordrecht : Foris Publications Holland.3300 AM.

Groenendael, Clara van. Victoria M. 1998 Released From Kala's Grip. A wayang Exorcism Performance from East Java. Series .Editor: Joan Suyenaga. The Lontar Foundation, Jakarta.

Koentjaraningrat. 1984. Kebudayaan Jawa. Jakarta: Balai Pustaka.

Koentjaraningrat. 1985.Ritus Peralihan di Indonesia. Jakarta: Balai Pustaka.

Lord, A.B. 1960. The Singer of Tales. Cambridge,Mass:Harvard University Press.

Mariani, Lies. 2004. Penggambaran Adegan Relief Cerita Bertemakan lukat Pada Bangunan Suci Masa Singhasari-
Majapahit (Abad 13-5 Masehi): Suatu Ritus-Upacara Peralihan.(Tesis). FIBUI.Depok.

Mariani, Lies.2012.Ruwatan Di Taman Mini Indonesia Indah: Kajian Dinamika Ruwatan Murwakala.Makalah The4th. International Confernce on Indonesian Studies(Bali, 9-10 Februari 2012). FIB.UI.

Padmapuspita, Ki. Tt.Candi Sukuh Dan Kidung Sudamala.Proyek Pengembangan Media Kebudayaan. Ditjen.Kebudayaan Dep Pendidikan dan Kebudayaan.RI.

Pudentia MPSS. 2007. Hakikat kelisanan dalam tradisi Melayu Mak Yong. Depok: fakultas Ilmu Pengetahuan Budaya (FIB)UI.

Pudentia MPSS.2008 Metodologi Kajian Tradisi Lisan. Penerbit Asosiasi Tradisi Lisan (ATL). Jakarta.

Pigeaud, Th. 1937. Serat Pangroewatan, tjetjepenganipun Dalang ing padoesoenan katedak. R. Tanaja ing Soerakarta. (PN. Kode Koleksi. G.193).

Pigeaud, Th 1937. Tjaranipoen Doekoen Bilih Angroewat. (PN.Kode Koleksi.G.191)(hal;1-36).

Roger Toll, dan Pudentia. 1995. Tradisi Lisan Nusantara: Oral Traditions from The Indonesia Achipelago a Three-Directional Approach. Dalam Warta ATL Edisi Perdana. Jakarta:ATL

Santiko, Hariani, 1980 Ruwat: Tinjauan dari sumber-sumber kitab Jawa Kuna dan Jawa Tengahan. Seri Penerbitan Ilmiah. FSUI.

Sutarno. 1995 Ruwatan Di Daerah Surakarta. Penerbit CV. Cendrawasih, IKAPI. Surakarta

Sutarno. 2007. Sejarah Pedalangan. Penerbit Institut Seni Indonesia (ISI) Surakarta

Subalidinata, R.S. 1990 Ruwatan Dalam Pewayangan. Dalam Ruwatan Dan Tokoh Kala Dalam Cerita Pewayangan. Lembaga Javanologi. Yayasan Ilmu Pengetahuan dan Kebudayaan Panunggalan Bekerjasama dengan Balai Kajian Sejarah Dan Nilai Tradisional.Yogyakarta.

Sedyawati, Edi. 1981.Pertumbuhan Seni Pertunjukan. Penerbit Sinar Harapan. Jakarta.

Sedyawati, Edi. 1996.Kedudukan tradisi lisan dalam ilmu-ilmu sosial dan ilmu-ilmu budaya.dalam Warta ATL Edisi II/Maret. Jakarta: Asosiasi Tradisi Lisan.

Sedyawati, Edi. 2008. Sastra dalam Kata, Suara, Gerak, dan Rupa.Dalam 
Metodologi Kajian Tradisi Lisan. Ed.

Pudentia. Jakarta: Penerbit Asosiasi

Tradisi Lisan (ATL).

Tanaya.1937 Serat Pangroewatan.

Tjetjepenga-nipoen Dalang ing padoesonan.

Tanaya.1937. Tjaranipoen Doekoen Bilih Angroewat.

Thoyib,Adiningrat Mas'ud.tt. Murwakala \&

Ruwatan gagrak Surakarta

Hadiningrat.Penerbit Renaissance

Nusantara Foundation.

Zoetmulder. 1985. Kalangwan: Sastra Jawa

Kuno Selayang Pandang. Jakarta: Penerbit

Djambatan.

\section{Sumber Surat Kabar dan Majalah}

Jaya Baya: kalawarti minggon basa Djawa.

Yayasan Djojobojo, Surabaya. 2010 65.113No.08.Minggu IV Oktober 2010 ( hal 18-19).

Media Indonesia. 2012. Ruwatan Rambut Gimbal di Bumi Nirwana. Media

Indonesia. Minggu, 15 Juli 2012

Cempala: Jagad Pedalangan Dan

Pewayangan. Edisi: Murwakala Ruwatan. (Oktober-1995) PEPADI-TMII. Jakarta.
Sumber naskah-naskah dan Tulisan Upacara Ruwatan Murwakala berbahasa

Jawa

“Lampahan Wayang Purwa” Jilid I. 1989. dalam Pakem Pedalangan R.S.

Probohardjono. Surakarta: Penerbit CV. Ratna, 1989.

\section{Sumber Kamus Jawa}

Mardiwarsito.L 1990.Kamus Jawa Kuna Indonesia. Flores, Ende: Nusa Indah.

Poerwadarminta, W.J.S. 1937. Baoesastra Djawa. Groningen: Kaetjap ing Pengetjapan J.B. Wolters' uitgevers Maatschappij. Batavia.

Pigeaud.Th. 1937.Javaans Nederlands Handwoordenboek. Groningen: WoltersNoordhoff.Jogjakarta.

Zoetmulder, P.J. \& S.O. Robson. 1995. Kamus Jawa Kuna-Indonesia I A-O, penerjemah Darusuprapto, Sumarti.

Suprayitna. Old Javanese-English Dictionary,I A-O) Jakarta: Gramedia Pustaka Utama 